\title{
BMJ Global Health COVID-19: an opportunity to rethink global cooperation in higher education and research
}

\author{
Simone Buitendijk, ${ }^{1}$ Helen Ward, ${ }^{1}$ Gideon Shimshon, ${ }^{1}$ Amir H Sam, ${ }^{1}$ \\ Dhananjaya Sharma, ${ }^{2}$ Matthew Harris (i) ${ }^{3}$
}

To cite: Buitendijk S, Ward H, Shimshon G, et al. COVID-19: an opportunity to rethink global cooperation in higher education and research. BMJ Global Health 2020;5:e002790. doi:10.1136/ bmjgh-2020-002790

Handling editor Seye Abimbola

Received 30 April 2020

Revised 18 June 2020

Accepted 22 June 2020

Check for updates

(c) Author(s) (or their employer(s)) 2020. Re-use permitted under CC BY-NC. No commercial re-use. See rights and permissions. Published by BMJ.

${ }^{1}$ Imperial College London, London, UK

${ }^{2}$ Government NCSB Medical College, Jabalpur, India ${ }^{3}$ Department of Primary Care and Public Health, Imperial College London, London, UK

Correspondence to Dr Matthew Harris; m.harris@imperial.ac.uk
The severe acute respiratory syndrome coronavirus 2 pandemic is many terrible things, but it is also acting as a pilot study in global collaboration in several sectors. Many international corporations are working together rather than competing with each other to produce vaccines. There is large-scale exchange of medical and public health data and possible solutions using digital and online tools. A number of industries have pivoted their products and business models to respond to the pandemic. ${ }^{12}$ This is also an opportunity to challenge the model of competition between universities and transcend the traditional boundaries of knowledge production, dissemination and consumption. In a time like this we need universities more than ever as centres of research, learning and global good. However, according to UNESCO, most governments have temporarily closed educational institutions to contain the spread of COVID-19, impacting about $91 \%$ of students globally, ${ }^{3}$ and many universities are facing an uncertain future and financial losses because of a decline in numbers of fee-paying overseas students seeking to come to their campuses. ${ }^{4}$ While many universities have been responsive and agile in developing remote learning during the crisis, simply putting traditional in-classroom teaching online will not be enough to get these students back in the longer term. Furthermore, the crisis demonstrates that we need global solutions to global challenges and universities need to work harder and better at collaborating. We have to rapidly become more empathic, less competitive and more networked in our research and educational activities and in our ability to take care of each other on a global scale. Researchintensive universities are pivotal in order to train medical and public health students, policy makers and clinicians across continents to become highly effective and adaptive,
Summary box

The severe acute respiratory syndrome coronavirus 2 pandemic presents significant challenges for higher education and clinical training, normally based on face-to-face interaction, and an opportunity to improve international cooperation.

- We propose three strategies to ensure that, when we emerge from this crisis, global cooperation in higher education and research is the norm: move to online, digital learning; enhanced networks with institutions from the Global South; and a reformed funding and reward structure.

- Tackling global issues collaboratively, starting with COVID-19, we will be so much better placed to solve the many issues, known and unknown, that our planet will undoubtedly face in decades to come, including the next pandemic.

internationally collaborative workers that can tackle both the present crisis and future ones.

We propose three strategies to ensure that, when we emerge from this crisis, global cooperation in higher education and research is the norm.

First, while there will always be fundamental benefits from inperson clinical practice and training, the move to online delivery of highquality higher education at a scale that started around 10 years ago can be of enormous help in producing globally relevant learning materials that present and future medical workers need, regardless of where they study or work. Online does not have to be impersonal as it can contain strong elements of engagement and community. It can complement 'learning' by 'doing' in medicine and public health. In response to the present crisis the Penn State University has moved biology and physics labs online, ${ }^{5}$ Tsinghua University has developed home lab kits, ${ }^{6}$ Coursera, EdX and FutureLearn have offered all their online courses for free, ${ }^{7-9}$ and Imperial College has 
both established a virtual space for surgeons in the front line of the COVID-19 crisis to work together ${ }^{10}$ and has for the first time anywhere delivered high-stakes finalyear medical school assessments remotely as digital openbook exams. ${ }^{11}$

Online delivery before the COVID-19 crisis was already creating exciting global groups of medical students and learners and enabled collaboration and cutting-edge, research-led teaching that was previously not possible in a regular clinic or on-campus classroom. Now, with severely limited mobility that may last for a long time, that type of delivery may not only be the best quality globalised medical education, but the only sustainable type. Completed by internships to form the professional identity of the student, universities with the right vision will use the present crisis to build an online offering that is high quality, designed for a different mode of delivery, for a different and much larger audience, perhaps even for a different world.

Globally, the demand for medical and health education is estimated to grow from 50 million students at present to 130 million in $2030 .{ }^{12}$ Online core medical education can be done at scale, in collaborative efforts between universities in the Global North and Global South, and can meet the increasing demand for globally relevant learning, both from students and from practising healthcare workers regardless of where they live and work. Of course we will also have to test models to combine the best online learning with safe opportunities to develop and train in necessary practical skills and hands-on aspects of medicine. Technological advances in online teaching and assessments, in simulation, and in medical augmented and virtual reality, all of those possible even through use of smart phones, will enable learners from across the world to gain advanced skills and receive high-quality medical education. More and more exciting digital innovation will be developed in the years to come, enabling high-quality, online, globally relevant medical education and training. Imperial College London's recently launched fully online Global Master in Public Health attracts students from across the globe and from a large range of backgrounds. The degree can be more flexible than an on-campus programme, and students can choose pathways that are most relevant to them and can combine studying with work and family responsibilities. The inclusion of a strong research element allows for groups of students across the world to share approaches and topics and to collect data in multiple locations, potentially creating lasting communities of practice.

Second, universities from the 'Global South' need to be more involved in a global network to exchange and co-create much needed globally relevant medical and public health information and education. We need to co-develop and share our medical and public health education at an unprecedented scale and almost in real time, between rich universities in the Global North and less well-off ones in the Global South. Knowledge production needs to take place in respectful collaboration between the networked partners. Both the Western and the less rich universities should in equal measure be the producers and recipients of locally relevant medical and public health knowledge and teaching. The clinical skills and acumen of low-income countries' clinicians oftentimes honed through the absence of diagnostic support technologies are particularly important to leverage. Equally, medical schools in the Global South can provide a rich database for infectious and communicable diseases and for public health approaches that can be taught in universities in the Global North. Modules produced by a university in the Global North, for instance, can be adapted by including local knowledge and needs by the partner university and subsequently offered back to the university that created the original module. Frugal innovation approaches to health challenges can be designed and taught by Global South universities. For such a co-creative model to work, formal agreement on mutual recognition of credit is needed. Students' research projects should be collaborative between the partner universities to lead to research outcomes that are transformative and locally and globally pertinent. Funding models have to be designed to enable staff and students from Global South universities to fully and equally participate.

The COVID-19 crisis teaches us that solutions can and should come from anywhere. ${ }^{13}$ Together universities should produce modules or entire (medical) degree programmes with use of a collaborative knowledge base that is globally, nationally and locally relevant. We may call it 'reverse education' which will, especially if it is informed by its sibling 'reverse innovation', be important in tackling global issues collaboratively, starting with COVID-19. ${ }^{14-16}$ To make this work, we should increase our present global COVID-19 collaborative mindset and let go of the competitive behaviour that in the past has created disparities between universities in the Global North and the Global South. Top-ranked universities need to focus on building strong networks in collaborative partnerships with universities in the Global South that may have less status, money and power, but have drive and talent, invaluable local knowledge, and a huge need to train people with cutting-edge, globally relevant, research-based education.

For that to work, we need a funding and reward model that increases global cooperation between higher educational institutions, both in research and in teaching. Current funding structures and publishing traditions around authorship in particular favour universities in the Global North and create unhelpful knowledge and status hierarchies. Those, in turn, undermine the efforts of talented scientists, scholars and university teachers from elsewhere. Further, the perceived higher status of universities in the Global North disproportionately draws talented international students to their degree programmes. ${ }^{17-22}$ We should rethink and indeed disband university rankings, replace authorship positions with statements of contribution, and judge our researchers and educators based on the full range of activities, 
whether through interdisciplinary research and innovative globally relevant education or through essential contribution of pure science, social science, humanities and arts to global scholarship and humanity.

Even before the COVID-19 crisis, our planet was already facing enormous challenges, such as climate change and increasing inequality. Countries situated in the Global South are being impacted more severely and it is likely that they will also be, by the COVID-19 crisis, at least from the economic and social impact of mitigation strategies. These increasing problems can only be solved by including the voices of scholars and teachers in the Global South since they best understand their local context. If we get it right in the present crisis, we will be so much better placed to solve the many issues, known and unknown, that our planet will undoubtedly face in decades to come, including the next pandemic. We must not miss this opportunity to accelerate our global cooperation in higher education and research.

Twitter Matthew Harris @drmattjharris

Acknowledgements Imperial College London is grateful for the support from the NW London NIHR Applied Research Collaboration and the Imperial NIHR Biomedical Research Centre.

Contributors SB and MH wrote the first draft. All authors reviewed the subsequent draft for significant intellectual content and approved the final version.

Funding MH is supported in part by the NW London National Institute for Health Research (NIHR) Applied Research Collaboration. The views expressed in this publication are those of the authors and not necessarily those of the NIHR or the Department of Health and Social Care.

Competing interests $\mathrm{MH}$ is a non-executive director of Primary Care International. Patient consent for publication Not required.

Provenance and peer review Not commissioned; externally peer reviewed. Data availability statement № additional data are available.

Open access This is an open access article distributed in accordance with the Creative Commons Attribution Non Commercial (CC BY-NC 4.0) license, which permits others to distribute, remix, adapt, build upon this work non-commercially, and license their derivative works on different terms, provided the original work is properly cited, appropriate credit is given, any changes made indicated, and the use is non-commercial. See: http://creativecommons.org/licenses/by-nc/4.0/.

ORCID iD

Matthew Harris http://orcid.org/0000-0002-0005-9710

\section{REFERENCES}

1 Coronavirus: Vodka company to make 24 tons of hand sanitisers. Available: https://www.indiatoday.in/trending-news/story/ coronavirus-vodka-company-to-make-24-tons-of-hand-sanitisers1658956-2020-03-24 [Accessed 24 Mar 2020].

2 Gsk, Sanofi join forces to develop COVID19 vaccine. Available: http://www.pharmatimes.com/news/gsk,_sanofi_join_forces_to_ develop_covid-19_vaccine_1338323

3 UNESCO Institute for statistics. Available: http://data.uis.unesco.org/

4 Universities brace for huge losses as foreign students drop out'. Available: https://www.theguardian.com/education/2020/apr/11/ universities-brace-for-huge-losses-as-foreign-students-drop-out? utm_term=Autofeed\&CMP=twt_gu\&utm_medium\&utm_source= Twitter\#Echobox=1586621026

5 'Virtual experiments and mailed equipment: how professors are moving labs online'. Available: https://www.thedp.com/article/2020/ 03/labs-online-penn-professors-biology-chemistry-physics

6 X Cloud Technologies. Available: http://leishiyan.x-cloud.cc/

7 Take student learning online in response to coronavirus. Available: https://www.coursera.org/coronavirus

$8 \mathrm{EdX}$ and its Members use cookies and other tracking technologies for performance, analytics, and marketing purposes. Available: https://www.edx.org/covid-19

9 FutureLearn and its global partners respond to COVID-19, including a free online COVID-19 course from the London School of Hygiene \& Tropical Medicine. Available: https://www.futurelearn.com/info/ press-releases/futurelearn-and-its-global-partners-respond-tocovid-19-including-a-free-online-covid-19-course-from-the-londonschool-of-hygiene-tropical-medicine

10 Research and education to fight COVID-19. Available: https://www. pansurg.org/

11 Medical students take final exams online for first time, despite student concern. Available: https://www.theguardian.com/education/ 2020/mar/22/coronavirus-forces-medical-students-sit-final-examsonline

12 McKinsey global Institute, jobs lost, jobs gained: workforce transitions in a time of automation. Available: https://www.mckinsey. $\mathrm{com} / \sim /$ media/mckinsey/featured\%20insights/Future\%20of\% 200rganizations/What\%20the\%20future\%20of\%20work\%20will\% 20mean\%20for\%20jobs\%20skills\%20and\%20wages/MGI-JobsLost-Jobs-Gained-Report-December-6-2017.ashx

13 Harris M, Bhatti Y, Buckley J, et al. Fast and frugal innovations in response to the COVID-19 pandemic. Nat Med 2020;26:814-7.

14 Skopec M, Issa H, Harris M. Delivering cost effective healthcare through reverse innovation. BMJ 2019;367:16205.

15 Bhatti Y, Taylor A, Harris M, et al. Global lessons in Frugal innovation to improve health care delivery in the United States. Health Aff 2017:36:1912-9.

16 Marine Hadengue Nathalie de Marcellis-Warin Thierry Warin. " Reverse Innovation A Systematic Literature Review ". International Journal of Emerging Markets 2017;12.

17 Harris M, Marti J, Watt $\mathrm{H}$, et al. Explicit bias toward High-IncomeCountry research: a randomized, blinded, crossover experiment of English clinicians. Health Aff 2017;36:1997-2004.

18 Skopec M, Issa H, Reed J, et al. The role of geographic bias in knowledge diffusion: a systematic review and narrative synthesis. Res Integr Peer Rev 2020;5:2.

19 Cash-Gibson L, Rojas-Gualdrón DF, Pericàs JM, et al. Inequalities in global health inequalities research: a 50 -year bibliometric analysis (1966-2015). PLoS One 2018;13:e0191901.

20 Pan RK, Kaski K, Fortunato S. World citation and collaboration networks: uncovering the role of geography in science. Sci Rep 2012;2:902.

21 Lokugamage AU, Ahillan T, Pathberiya SDC. Decolonising ideas of healing in medical education. J Med Ethics 2020;46:265-72.

22 Hunt D, Klamen D, Harden R. The ASPIRE-to-Excellence program: a global effort to improve the quality of medical education. Academic Medicine 2017;93. 